\title{
Etiologies of Chronic Renal Failure in Adolescent Patients at the University Hospital of Brazzaville
}

\author{
R. Loumingou ${ }^{1,2}$, J. Kambourou ${ }^{1,3}{ }^{*}$, B. Diall ${ }^{3}$, A. Mbika Cardorelle ${ }^{1,3}$ \\ ${ }^{1}$ Faculty of Health Sciences, University Marien Ngouabi, Brazzaville, Congo \\ ${ }^{2}$ Department Nephrology, University Hospital of Brazzaville, Brazzaville, Congo \\ ${ }^{3}$ Department of Pediatrics Older Children, University Hospital of Brazzaville, Brazzaville, Congo \\ Email: *judycokam@yahoo.fr
}

How to cite this paper: Loumingou, R., Kambourou, J., Diall, B. and Cardorelle, A.M. (2020) Etiologies of Chronic Renal Failure in Adolescent Patients at the University Hospital of Brazzaville. Open Journal of Pediatrics, 10, 168-174.

https://doi.org/10.4236/ojped.2020.101016

Received: December 28, 2019

Accepted: March 3, 2020

Published: March 6, 2020

Copyright $\odot 2020$ by author(s) and Scientific Research Publishing Inc. This work is licensed under the Creative Commons Attribution International License (CC BY 4.0).

http://creativecommons.org/licenses/by/4.0/

\begin{abstract}
Objectives: The aim of our work was to identify the etiologies of chronic renal failure in adolescent patients. Patients and Methods: This is a descriptive cross-sectional retrospective study that included adolescents aged 10 to 19 years hospitalized between January 2014 and December 2017 in the department of nephrology at the University Hospital of Brazzaville. The CRF was defined according to the ANAES criteria by an estimated glomerular filtration rate less than $60 \mathrm{ml} / \mathrm{min} / 1.73 \mathrm{~m}^{2}$ of body surface. Results: Forty cases of CRF were collected, representing a prevalence of $4.9 \%$. The average age was $16.32 \pm 3.64$ years and the sex ratio was 3 . The most common mode of discovery was edematous syndrome $62.5 \%$. The most common etiology was glomerular nephropathies $60 \%$, hereditary nephropathies $25 \%$ and malformative uropathies in $15 \%$. Ten patients (25\%) had moderate CFR at admission, $62.5 \%$ had severe CRF, $12.5 \%$ had terminal CFR and all of them died during the year. Conclusion: Epidemiological data CRF in adolescent patients in developing countries are scarce and limit treatment. Glomerular pathologies represent the most frequent etiology. Early treatment of chronic renal failure in childhood and multidisciplinary collaboration between pediatrician and nephrologist are necessary.
\end{abstract}

\section{Keywords}

Adolescent, Etiologies, Chronic Renal Failure

\section{Introduction}

Chronic renal failure (CKD) is defined as a decrease in glomerular filtration rate 
(GFR) of less than $60 \mathrm{ml} / \mathrm{min} / 1.73 \mathrm{~m}^{2}$ of body surface evolving for more than 3 months [1]. This decrease is permanent and irreversible. Chronic renal failure (CKD) is a real public health problem due to its continuous increase and its serious human and socioeconomic consequences [2].

Its incidence differs according to the country, the age of the child and the stage of development [3]. European epidemiological studies report an incidence varying from 6 to 22 new cases/million inhabitants/year and a prevalence of 55 to 75 per million children of the same age [4] [5] [6] [7]. In developing countries, particularly in Africa, few studies have been devoted to chronic renal failure in children. In Côte d'Ivoire, chronic renal failure represented $17.39 \%$ of all children hospitalized between 1992 and 1997 and 83.33\% of these children were adolescents [8]. In Congo, data on chronic kidney disease in children have not been found.

The etiologies of CKD in children are dominated by three main groups of pathologies: congenital anomalies of the kidney and urinary tract $(40 \%-60 \%)$, hereditary nephropathies (15\% - 25\%) and acquired causes (15\% - 25\%) [9].

In order to optimize prevention and care in our work environment, we report a hospital series of 40 adolescents; the objective being to list the etiologies.

\section{Patients and Methods}

This was a retrospective, transversal, descriptive study which took place from January 1, 2014 to December 31, 2017, i.e. in 4 years in the departments of nephrology and pediatrics older children at the Brazzaville University Hospital. Our study population consisted of the records of all children aged five to 19 years hospitalized in the aforementioned services during the study period. Workable records of adolescents admitted for chronic renal failure (CKD) have been included.

The definition of adolescent used was that of the World Health Organization (WHO), i.e. an individual between the ages of 10 and 19. The CRI was defined by a creatinemia clearance determined according to the COCKROFT formula which was less than $60 \mathrm{ml} / \mathrm{min}$ evolving for more than 3 months. The files of patients under the age of 10 , those over the age of 19 and acute renal failure (AKI) were not included in the study. So we classified the CRI according to the stages of severity: moderate CRI when the GFR was between 30 and $59 \mathrm{ml} / \mathrm{min}$, severe for a GFR between 15 and $29 \mathrm{ml} / \mathrm{min}$ and terminal when the GFR was below 15 $\mathrm{ml} / \mathrm{min}$.

Based on these criteria, 40 files of patients hospitalized for CKD were selected for this work. Our data sources were medical records and hospital records.

A pre-established survey form, completed by the same investigator, allowed the data to be collected.

For each file, the variables studied were: age, sex, circumstances of discovery, mode of disclosure, etiology, stage of severity of CKD and course.

Microsoft Excel 97 and Epi Info software version 3.5.1 were used for data 
analysis, Pearson $\mathrm{Chi}^{2}$ test was used to compare qualitative variables. The significance threshold was set at $p<0.05$.

\section{Results}

\subsection{Frequency of IRC}

During the study period, 1250 patients were hospitalized, including 812 cases of chronic renal failure (CKD), a prevalence of $65 \%$. Of these cases of CRF, 40 were adolescents, a prevalence of $4.9 \%$. The distribution of patients with CKD according to the year of diagnosis is shown in Table 1 .

\subsection{Age and Gender}

The 40 patients were divided into 30 boys and 10 girls, the sex ratio $\mathrm{M} / \mathrm{F}$ was equal to $3(p<0.05)$. The average age was $16.31+/-3.64$ years $(11-19$ years $)$.

Table 2 shows the distribution of patients according to age groups.

The 17 - 19 age group accounted for $52.5 \%$ of the sample, followed by the 14 16 age group (30\%) and the 11 - 13 age group with $17.5 \%$.

\subsection{Circumstances of Discovery}

The circumstances of discovery of CKD were: edema syndrome $62.5 \%(n=25)$, high blood pressure $25 \%(n=10)$, oligo-anuria $20 \%(n=8)$, gross hematuria $5 \%$ $(\mathrm{n}=2)$ and rapidly progressive renal failure $2.5 \%(\mathrm{n}=1)$. A patient could have several circumstances of discovery.

\subsection{Etiologies of IRC}

The etiologies found were: glomerular nephropathies 60\% $(\mathrm{n}=24)$ including nephrotic syndrome associated with chronic glomerulonephritis 50\% ( $\mathrm{n}=12)$, HIV nephropathy 25\% $(n=6)$ and renal lithiasis 25\% $(n=6)$; hereditary nephropathies $25 \%(n=10)$ and malformative uropathies $15 \%(n=6)$. Among hereditary nephropathies, $15 \%$ were due to sickle cell nephropathy and $10 \%$ were attributed to congenital nephropathy, in particular an atrophic kidney. The $15 \%$ of urological malformations were $10 \%$ of uretero-hydronephrosis and $5 \%$ of vesicoureteral reflux.

Table 1. Number of cases of chronic renal failure by year of study.

\begin{tabular}{ccc}
\hline Years & Number of cases & Percentage \\
2014 & 14 & $35 \%$ \\
2015 & 15 & $37.5 \%$ \\
2016 & 7 & $17.5 \%$ \\
2017 & 4 & $10 \%$ \\
Total & 40 & $100 \%$ \\
\hline
\end{tabular}


Table 2. Distribution of patients according to their age group.

\begin{tabular}{ccc}
\hline Year & Number of cases & Percentage \\
\hline $11-13$ years & 7 & $17.5 \%$ \\
$14-16$ years & 12 & $30 \%$ \\
$17-19$ years & 21 & $52.5 \%$ \\
Total & 40 & $100 \%$ \\
\hline
\end{tabular}

\subsection{Severity Stages}

Ten patients (25\%) had moderate CKD at admission, 25 patients $(62.5 \%)$ had severe CKD, and 5 patients (12.5\%) had terminal CKD.

\subsection{Evolutionary Aspects}

All patients had died during the year, i.e. 100\% lethality.

\section{Discussion}

This study, the objective of which was to identify the etiologies of adolescent chronic renal failure is a single-center study; the results cannot therefore be extrapolated to the national level. Likewise, the retrospective nature of this study constitutes a limit to it insofar as the collection of data cannot be exhaustive.

The incidence and prevalence of CRF are unknown. The few studies on CRF in pediatrics have only focused on subjects aged 0 to 15 years. In our study, we included 40 cases of CRF, a prevalence of $4.9 \%$. Studies on the epidemiology and the causes of chronic renal failure face several problems. To be comparable, the epidemiological surveys concerning adolescent renal patients must involve the same population: those of children aged 10 to 19 with CRF. The prevalence of $\mathrm{CRF}$ in children and adolescents has published regularly in Western Europe and North America thanks to the establishment of registers of chronic renal failure [10]. The American Kidney Disease Registry, the North American Pediatric Renal Trials and Collaborative Studies (NAPRTCS) 2008 estimate that the prevalence of chronic renal failure (CRF) is $32 \%$ in patients aged 0 - 19 years [11]. The lack of a renal failure registry is a fact in most developing countries, which affects the underestimation of this incidence.

The average age of our patients at the time of diagnosis of CRF was $16.31 \pm$ 3.64 years and the age distribution revealed a predominance of cases in the 17-19 years age group (52.5\%). The higher incidence of CRF in older children over the age of 10 was also noted in Tunisia, Senegal and Côte d'Ivoire, respectively $57.55 \%, 64.15 \%, 83.33 \%$ [8] [12] [13]. The incidence was almost twice higher in children aged 15 to 19 (28 for MARP) than in children aged 10 to 14 (14 for MARP) according to the ITALKID register [4]. The high age of the patients could be explained by the late diagnosis of the disease as was the case in our study where $62.5 \%$ of CRFs were diagnosed at a severe stage. In our series, $75 \%$ of the patients were men with a sex ratio of 3 . Two-thirds of the patients in the 
NAPRTCS registry of 2008 and in the ITALKID project database are boys [10]. This male predominance could be explained by the higher frequency of glomerulopathies and urological malformations in boys.

Clinically, renal edematous syndrome, high blood pressure, macroscopic hematuria were present in the majority of patients. These clinical signs most often indicate an acquired nephropathy according to Llanas et al. [9]. These results require screening for chronic renal failure in our context. This screening involves the use of urine strips and a systematic measurement of blood pressure.

Etiologically, glomerular nephropathies represented the main etiology of CRF in the patients in our study with a frequency of $60 \%$. We did not study their distribution by histological type because the renal biopsy was not performed. Corticosteroid-resistant idiopathic nephrotic syndrome is a glomerular disease that sometimes begins in childhood, often progresses through adolescence and represents the first in adolescent CRF [14] [15]. Other etiologies have been found in our series. Sickle cell anemia, a common hereditary hemoglobinopathy in our regions, is a possible cause of adolescent CRF [16] [17]. A regular dosage of microalbuminuria allows early detection of renal disease [18]. The incidence of congenital nephropathies is probably underestimated in our environment due to the limited means of investigation. Cases of CRF secondary to HIV-associated nephropathy in two adolescents in genital sexual activity are probably linked to kidney damage directly induced by HIV infection [19], toxicity of antiretroviral therapy [20] and poor adherence therapy in older adolescents characterized by parental lassitude and participation [21]. Chronic kidney damage due to renal lithiasis is linked to the atypical nature of kidney stones in children, which rarely manifests as typical renal colic, but rather by vague abdominal pain, urinary tract infections and macroscopic hematuria [22] [23] [24] [25] making the diagnosis more difficult. CRF secondary to malformative uropathies is linked to the existence of recurrent urinary tract infections which induce progressive damage of the renal parenchyma [26].

In terms of evolution, management of the disease remains a challenge because the mortality rate is very high ( $100 \%$ during the year of admission). The zero survival rate in our work could be explained on one hand by the delay in the care of children due to the limited financial resources forcing parents to self-medicate and take their children to consultations in small health facilities, on the other hand by the unavailability of pediatric dialysis units. In addition, kidney transplantation is not yet available in Congo.

\section{Conclusion}

Epidemiological data CRF in adolescent patients in developing countries are rare and hinder efforts to improve its management. Glomerular pathologies represent the most frequent etiology. Early treatment of chronic renal failure in childhood and multidisciplinary collaboration between pediatrician and nephrologist are necessary. 


\section{Conflicts of Interest}

The authors declare no conflicts of interest regarding the publication of this paper.

\section{References}

[1] ANAES (2002) Diagnostic de l'insuffisance rénale chronique chez l'adulte.

[2] Pillot, P. and Kleinclauss, F. (2009) Transplantation rénale. La transplantation rénale. progrès en urologie, 19, 254-259.

[3] Allain-Launay, E. and Roussey-Kesler, G. (2011) Insuffisance rénale chronique de l'enfant. La Presse Médicale, 40, 1028-1036. https://doi.org/10.1016/j.lpm.2011.05.025

[4] Warady, B.A. and Chadha, V. (2007) Chronic Kidney Disease in Children: The Global Perspective. Pediatric Nephrology, 22, 1999-2009.

https://doi.org/10.1007/s00467-006-0410-1

[5] Ardissino, G., Dacco, V., Testa, S., Bonaudo, R., Claris-Appiani, A., Taioli, E., et al. (2003) Epidemiology of Chronic Renal Failure in Children: Data from the ItalKid Project. Pediatrics, 111, 382-387. https://doi.org/10.1542/peds.111.4.e382

[6] Deleau, J., Andre, J.L., Briancon, S. and Musse, J.P. (1994) Chronic Renal Failure in Children: An Epidemiological Survey in Lorraine (France) 1975-1990. Pediatric Nephrology, 8, 472-476. https://doi.org/10.1007/BF00856534

[7] Esbjorner, E., Berg, U. and Hansson, S. (1997) Epidemiology of Chronic Renal Failure in Children: A Report from Sweden 1986-1994. Swedish Pediatric Nephrology Association. Pediatric Nephrology, 11, 438-442. https://doi.org/10.1007/s004670050312

[8] Lagou, D.A., Gnionsahe, D.A. and Tiaw, M. (2006) L’insuffisance rénale chronique chez l'enfant en milieu hospitalier en côte d'ivoire: Etude de 24 cas. Revue Internationale des Sciences Médicales, 8, 18-22.

[9] Llnas, B. and Godron, A. (2012) Quand penser à l'insuffisance rénale chronique chez l'enfant? Archives de Pédiatrie, 19, 209-210. https://doi.org/10.1016/S0929-693X(12)71215-0

[10] Ardissino, G., Dacco, V., Testa, S., Bonaudo, R., Claris-Appiani, A., Taioli, E., Marra, G., Edefonti, A. and Sereni, F. (2003) Epidemiology of Chronic Renal Failure in Children: Data from the ItalKid Project. Pediatrics, 111, e382-e387. https://doi.org/10.1542/peds.111.4.e382

[11] NAPRTCS Annual Reports 2008. http://www.emmes.com/study/ped/annlrept/annlrept.html

[12] Kamoun, A., Jawahdou, F., Hachicha, J., Abdal-lah, T.B., Maiz, H.B., Moussa, F.B. and Lakhoua, R. (1997) Causes de l'insuffisance rénale chronique terminale de l'enfant en Tunisie. Archives de Pédiatrie, 4, 196-198. https://doi.org/10.1016/S0929-693X(97)86175-1

[13] Kéita, Y., Sylla, A., Cissé, M.M., Lemrabott, A.T., Ndongo, A.A., et al. (2014) Aspects épidémiologiques, cliniques et évolutifs de l'insuffisance rénale chronique (IRC) chez l'enfant dans un hôpital pédiatrique Sénégalais. African Journal of Paediatric Nephrology, 1, 83-89.

[14] Del Rio, M. and Kaskel, F. (2008) Evaluation and Management of Steroid-Unresponsive Nephrotic Syndrome. Current Opinion in Pediatrics, 20, 151-156. https://doi.org/10.1097/MOP.0b013e3282f4e6e4 
[15] Shina, A. and Bagga, A. (2012) Nephrotic Syndrome. Indian Journal of Pediatrics, 79, 1045-1055. https://doi.org/10.1007/s12098-012-0776-y

[16] Guasch, A., Navarrete, J., Nass, K. and Zayas, C.F. (2006) Glomerular Involvement in Adults with Sickle Cell Hemoglobinopathies Prevalence and Clinical of Progressive Renal Failure. Journal of the American Society of Nephrology, 17, 2228-2235. https://doi.org/10.1681/ASN.2002010084

[17] Wigfall, D.R. (2000) Prevalence and Clinical Correlates of Glomerulopathiy in Children with Sickle Cell Disease. The Journal of Pediatrics, 36, 749-753.

[18] Dharnidharka, V.R., et al. (1998) Prevalence of Microalbuminuria in Children with Sickle Cell Disease. Pediatric Nephrology, 12, 475-478. https://doi.org/10.1007/s004670050491

[19] Peraldi, M.N. (2001) Physiopathologie de la néphropathie associée à l'infection par le VIH. Nephrology, 22, 297-298.

[20] Izzedine, H., Launey-vacher, V. and Derey, G. (2005) Antiviral Drug-Induced Nephrotoxicity. American Journal of Kidney Diseases, 45, 804-817. https://doi.org/10.1053/j.ajkd.2005.02.010

[21] Cardorelle, A.M., Toussoungamana-Peka, S.A., Miakassissa, C.M. and Okoko, A. (2014) Observance du traitement antiretroviral chez l'adolescent infecté par le VIH à Brazzaville. Archives de Pédiatrie, 21, 105-107. https://doi.org/10.1016/j.arcped.2013.10.011

[22] Jungers, P., Joly, D., Barbey, F., et al. (2004) ESRD Caused by Nephrolithiasis: Prevalence, Mechanisms and Prevention. American Journal of Kidney Diseases, 44, 799-805. https://doi.org/10.1016/S0272-6386(04)01131-X

[23] Alaya, A., Nouri, A. and Najjar, M.F. (2009) Urolithiasis in Tunisian Children: A Study of 100 Cases. Saudi Journal of Kidney Disease and Transplantation, 20, 1096-100.

[24] Polito, C., La Manna, A., Signoreiello, G., et al. (2009) Recurrent Abdominal Pain in Childhood Urolithiasis. Pediatrics, 124, 1088-1094. https://doi.org/10.1542/peds.2009-0825

[25] Hoppe, B. and Kemper, M.J. (2010) Diagnostic Examination of the Child with Urolithiasis or Nephrocalcinosis. Pediatric Nephrology, 25, 403-413. https://doi.org/10.1007/s00467-008-1073-x

[26] Lee, J.H., Son, C.H., Lee, M.S. and Park, Y.S. (2006) Vesicoureteral Reflux Increases the Risk of Renal Scars: A Study of Unilateral Reflux. Pediatric Nephrology, 21, 1281-1284. https://doi.org/10.1007/s00467-006-0147-x 